\title{
Politique
}

Politique

\section{André LAURENDEAU, Journal tenu pendant la Commission royale d'enquête sur le bilinguisme et le biculturalisme, Montréal, VLB éditeur, 1990, 385 p.}

\section{Denis Monière}

Numéro 18, automne 1990

URI : https://id.erudit.org/iderudit/040673ar

DOI : https://doi.org/10.7202/040673ar

Aller au sommaire du numéro

Éditeur(s)

Société québécoise de science politique

ISSN

0711-608X (imprimé)

1918-6584 (numérique)

Découvrir la revue

Citer ce compte rendu

Monière, D. (1990). Compte rendu de [André LAURENDEAU, Journal tenu

pendant la Commission royale d'enquête sur le bilinguisme et le biculturalisme,

Montréal, VLB éditeur, 1990, 385 p.] Politique, (18), 117-119.

https://doi.org/10.7202/040673ar d'utilisation que vous pouvez consulter en ligne.

https://apropos.erudit.org/fr/usagers/politique-dutilisation/ 
André LAURENDEAU, Journal tenu pendant la Commission royale d'enquête sur le bilinguisme et le biculturalisme, Montréal, VLB éditeur, 1990, 385 p.

Si le politicien peut par ses décisions marquer l'évolution des institutions d'un pays, l'intellectuel peut, lui, par la pensée, influencer profondément la façon de se définir d'une société et ainsi orienter ses choix collectifs. Si Trudeau a réussi à imposer sa vision centralisatrice du Canada, il n'a pas pour autant solutionné la crise de l'unité canadienne qu'avait diagnostiquée Laurendeau qui ne voyait d'avenir pour le Canada que dans la reconnaissance de la société distincte et l'attribution d'un statut particulier pour le Québec. Cette conception est restée bien vivante puisque la source intellectuelle du débat sur la société distincte qui était au centre de l'Accord du lac Meech remonte au Rapport de la Commission royale d'enquête sur le bilinguisme et le biculturalisme. C'est la genèse de cette Commission et de son rapport qui nous est livrée par Laurendeau dans le journal qu'il a tenu du 20 janvier 1964 au 3 décembre 1967.

L'ironie du sort a voulu que le même jour, soit le 19 mars 1990, soient lancés à Montréal le livre consacré aux années Trudeau et le journal de Laurendeau, deux livres qui reflètent deux visions différentes du Canada et du destin politique du Québec et qui nous rappellent que, 30 ans après la Révolution tranquille, la question du Québec n'est pas encore réglée.

Laurendeau avait accepté de suspendre sa carrière, de quitter son milieu, ses projets d'écriture et d'aller à Ottawa en pensant qu'il pourrait, par une approche rationnelle et informée de la situation, amener le reste du Canada à reconnaître la spécificité du Québec et à lui donner une dimension politique. À ses yeux, le 
bilinguisme n'était pas une conditions suffisante pour résoudre la crise canadienne. Il y avait une autre condition nécessaire: le biculturalisme. L'égalité des langues et des individus devait être complétée par l'égalité politique entre les deux peuples fondateurs. Mais ce projet sera écarté par Trudeau après son accession à la chefferie du Parti libéral.

Lire ce témoignage de Laurendeau dans le contexte de l'échec du lac Meech est une leçon éclairante sur les constantes de la vie politique canadienne, car on y retrouve tous les arguments qui ont marqué le débat constitutionnel depuis 1987 comme si le passage des ans n'avait en rien modifié la réalité des deux solitudes depuis les années 60 . On y retrouve, comme aujourd'hui, la francophobie des petites villes ontariennes et la farouche résistance des groupes ethniques de l'Ouest qui s'opposent au concept de la société distincte et réclament la reconnaissance du multiculturalisme. Rien de neuf au pays des éternels recommencements.

Ce journal, tenu de façon épisodique, nous décrit les émotions et les doutes qu'a éprouvés Laurendeau durant son long pélerinage en Canada. On y voit vivre et réfléchir un Laurendeau qui expose ses états d'âme, ses angoisses, ses colères et ses déchirements. Plus on progresse dans cette lecture, plus il nous communique sa lassitude et son découragement. Renouveler le fédéralisme dans le sens des intérêts du Québec lui apparaîtra de plus en plus comme une mission impossible.

Au-delà de son inestimable valeur historique, ce journal témoigne aussi de l'émergence de la recherche en sciences sociales au Québec. En effet, la démarche intellectuelle de Laurendeau procédait du postulat selon lequel l'adoption d'une bonne politique dépendait d'une connaissance rigoureuse du problème à résoudre. Laurendeau accordait une très grande importance à l'apport de la recherche dans son travail d'enquête. Il manifestait un souci constant d'accroître et de faire accepter par le Conseil du Trésor le budget consacré à la recherche. Ce budget représentera, en 19651966, $70 \%$ des dépenses de la Commission. Ces fonds ont servi à financer quantité de projets de recherche et à lancer la carrière universitaire de nombreux professeurs de sociologie, d'économie et de science politique. On apprend, par exemple, dans ce Journal que 
le politologue David Easton a été consulté par la Commission. On peut aussi saisir le rôle important joué par Léon Dion dans la définition de la stratégie de la recherche qui a, en définitive, orienté la conception même du Rapport.

L'intérêt de ce livre est aussi de nous faire pénétrer dans une impressionnante galerie de portraits politiques, où Laurendeau nous décrit les traits de caractère et les travers de nombreux hommes politiques qui oeuvraient tant sur la scène fédérale que dans les différentes provinces. La consignation des intrigues au journal $L e$ Devoir, des rencontres avec Pearson et les premiers ministres des provinces canadiennes, des conciliabules avec Lévesque, Pelletier et Marchand éclaire la petite histoire de l'élite politique canadienne et québécoise. Tous ceux qui comptaient dans le Québec politique d'alors y sont décrits sans complaisance et souvent avec humour.

Nul ne contestera que la Commission Laurendeau-Dunton a marqué un moment important de l'histoire politique canadienne. Mais paradoxalement, il n'y a pas encore eu d'étude systématique de cette Commission. À cet égard, la publication du Journal de Laurendeau constitue une pièce maîtresse incontournable pour celui qui voudrait analyser le fonctionnement d'une commission royale d'enquête. Laurendeau y expose la méthode de travail des commissaires, l'organisation des audiences publiques, les rapports entre les co-présidents et le premier ministre, les conflits entre certains ministres et des membres de l'opposition, les négociations avec le Conseil du Trésor, les relations avec les média, etc. Il faut souhaiter que ces matériaux de première main ne resteront pas inemployés.

Denis Monière

Université de Montréal 